\title{
Inflation Prediction and Inflation Volatility for Turkey
}

\author{
Hakan Eygü \\ Assistant Professor Ataturk University Department of Econometrics \\ Email: hakan.eygu@gmail.com \\ Hayati Aksu \\ Assistant Professor Ataturk University Department of Economic Policy \\ Email: haksu@atauni.edu.tr

\section{Muhammad Asad Ullah Moavia} \\ Master in Economic Policy Department of Economic Policy Ataturk University \\ Email: asad_economist1@yahoo.com
}

\section{Doi:10.5901/mjss.2016.v7n1p361}

\section{Abstract}

In early development of macroeconomic literature, policy makers focused on stability and constancy in monetary policy. However until now, policy makers are unable to make reliable prognostication in economic literature. The monetarist claims that under active monetary policy, inflation deviation should be unpredictable. Recently policy makers apply complicated econometric models such as Dynamic Stochastic General Equilibrium model (DSGE) and Bayesian VAR model in order to calculate an appropriate forecasting, yet, researchers prove these models very poor and hence these models do not give any further insights for policy making. The aim of this paper is too select an alternate technique that is robust, reliable, unbiased and efficient. For this reason, we estimate the inflation and its volatility for Turkey based on stochastic differential equation (SDE) under mathematical simulation. After computing stochastic parameters under SDE, our results establish that inflation volatility behaviour follow a systematic pattern from ex-ante to ex-post period for the Turkey. We can certainly reason that mathematical techniques are robust and give sufficient traces for inflation uncertainty rather than choosing DSGE and Bayesian VAR. Moreover, Euler Discretization and Unbiased Discretization process explain that the intensity for inflation volatility is recovered in the long run. Euler Discretization and unbiased Discretization confirm that inflation deviation is predictable for Turkey.

Keywords: Stochastic Differential Equation; Inflation Volatility; Simulation

\section{Introduction}

Risk measurement and risk forecasting are based on standard deviation hypothesis. Risk is superiorly judged via volatility element. The volatility in inflation is a risk, which gives awareness to businesses, traders, investors and consumers. The term volatility in inflation measures how much quickly the inflation changes and how much it changes the behaviour of people in an economy. Policy makers do not care about inflation rather than inflation volatility since inflation volatility changes the structure of an economy. For this reason, it is not a least demanding task to measure inflation volatility in order to craft systematic behaviour for different market players. Although different studies have been done so for to measure the inflation volatility such as ((EDGE \& GÜRKAYNAK, 2010 ; Berument \& Sahin, 2010; Berganza \& Broto, 2012; Castillo, 2014; Singor, Grzelak, van Bragt, \& Oosterlee, 2013; Ginindza \& Maasoumi, 2013; Clark \& Davig, 2011; Kim, 2004; Castelnuovo, 2010)) that provide an overview and postulate that under unsystematic monetary policy inflation deviation is unpredictable, while for systematic monetary policy, it is desirable to assume that government does not intervene in the monetary policy. In this paper, we choose a mathematical technique to measure inflation volatility and inflation prediction for Turkey. We follow the mathematical inference to establish the systematic and unsystematic monetary policy pattern for inflation. We demonstrate the consistency with other models such as Heston Process of SDEs, Ito's process, transition densities and Ornstein-Uhlenbeck process in SDE's. Policy makers use inflation targeting rate based on consumer price index for the Turkey. Historical evidence for Turkey explains that inflation rate was 8.17\% during December 2014 for Turkey; while the average rate of Turkey from 1968 to 2014 was 36.91\% until reach at peak 
level in May 1980 with $138.71 \%$ based on poor forecasting. We provide a robust technique SDE's to measure the firm prognostication for the inflation prediction and inflation volatility for the Turkey. The paper organizes with literature review, methodology, result discussion and conclusion respectively.

\section{Literature Review}

Inflation follows money demand and money supply mechanism with liquidity preference theory and money market equilibrium. It is generally assume that money supply is exogenous and fixed under central banking authorities; whereas money demand elaborates the consumers and investors behaviour through velocity of money. Money demand is divided into three parts which are transaction demand, precautionary and speculative demand for money. Transaction demand for money is a function of income in the money demand theory, while precautionary demand for money is a function of an income plus speculative demand for money is a function of interest rate. Money demand explains the financial asset holdings in the form of money. It includes M1, M2 and M3. M1 describes as store of value by bearing different assets in a market. M1 money provides liquidity for the market players such as consumers and producers. There is trade-off between liquidity for an asset and holding an asset in a market. Money demand is explained differently in classical and Keynesian perspective. Classical economists define the money demand under quantity theory of money in which income and velocity is constant; however price is directly proportional to money balance for classical economics. Money demand is criticized due to not having its microeconomics foundation by some renowned economists such as Baumol and Tobin. In order to validate the money demand function, numerous models are contributed in the macroeconomics literature such as cash in advance model which are based on microeconomics foundation. Economists are much concerned for the stability in money demand function. Numerous studies have been established to maintain the validity of money demand.

Dreger and Wolters (2014) forcast the money demand for Germany. The results explain that under the economic crisis inflation measures the better forecasting via vector autoregressive scheme. Arize, Malindretos, and Grivoyannis (2005) study inflation and its volatility under real money balance mechanism for underdeveloped and developing countries and found that inflation is negatively related with money demand during short and long run. Hossain (2010) analyze monetary policy mechanism for Bangladesh that monetary targetting is an appropriate measurement for Bangladesh, however its implementation can be more effective and stable, if Bangladeshi banks enhance their control over the money supply via inflationary pressure by avoiding nominal exchange rate intervention through foreign exchange market intervention. Pricea and Nasim (1999) study money demand stability function for the Pakistan. The study used the seemingly unrelated regression econometric model and found that there is a long run relationship of money demand via purchasing power parity analysis. Pricea and Nasim also examine that Pakistani monetary policy authority uses exchange rate as an anti-inflation mechanisim rather than accomodating PPP that explain, when CPI below the PPP condition, the exchange rate rises (depreciates) and monetary autority accomodates PPP deviation for the Pakistan. Bal (2000) estimat money demand using double log method and compare it with constant to semi-elasticity ("Cagan type money demand function") for US economy. Bal using double log function and explains that substaintial welfare gain for the US economy and found that in moving from zero inflation to the Friedman optimal inflation rate is the optimal inflation rate. Moreover, estimated welfare cost of inflation is proportional to money stock which classify proper specification of money demand function.

Oomes and Ohnsorge (2005) research on money demand for Russia and found that it is difficult to forecast the inflation for Russia due to dollarization economy. The study used the money demand stability analysis and explain that an excess supply of effective broad money present an inflationary pressure. Moreover, effective broad growth rate of money has the strongest and unrelent effect on inflation in short run for Russia. Budina, Maliszewski, Menil, and Turlea (2006); study the Cagan money demand function under Johansen co-integration approach for Romania and establish that there is long run co-integration relationship for Romainan economy. The study also explains that during liberalization, inflation and its volatility are based on monetary mechanism for the Romania. (De Santis, Favero, and Roffia, 2013) study cross border portfolio and M3 "velocity growth" for the Euro economies and found that output and interest rate were unstable during the crisis in 1970. El-Shagi and Giesen (2013) study multivariate state space network to find the short run impact of money on prices for USA. The results explain that federal response to financial crisis are inflationary nature and do not follow the monetary policy mechanism in the short run.

Apergis (1997) study the uncertainity factor for inflation in money demand equation by using Johansen cointegration technique for GREECE. The results explain that inflation uncertainity in GREECE follow the deragulation of the monetary system in terms of capturing the money demand structural inabilities. Jawadi and Sousa (2013) estimate money demand equation for USA and UK during Euro Era by applying the quantile regression and smooth transition regression and found that income and interest rate semi-elasticities are significantly differ from the OLS at the tail of the 
distribution. While, sensitivity of money demand with respect to inflation tends are larger when real money holdings are too low. Reynard (2007) examine systematic relationship between money, prices and output and conclude that price movements are always related to earlier monetary developments in any economy, while significant monetary movements are always track by consequent price movements. Basco, D'Amato, and Garegnani (2009) analyze money with price relationship for Argentia and found that money and price relationship holds during high inflationary period. (EDGE \& GÜRKAYNAK, 2010), forecast the monetary policy mechanism for Turkey and explain that, inflation deviation are unpredictable for Turkey. Moreover, (DSGE) and Bayesian VAR model proves poor forecasting for the Turkey.

\section{Methodology}

We use the monthly observations for the period of 2006 to 2013 from central bank of Turkey. We took inflation as a variable in order to measure the stochastic volatility for the Turkish economy. In order to calculate stochastic volatility which is "sigma", we apply (Generalized Conditional Autoregressive Heteroskedasticity) GARCH model. We then calculate the drift parameter "mu" from (Augmented Dickey Fuller Test) ADF and (Kwiatkowski-Phillips-Schmidt-Shin) KPSS tests. We found that inflation parameter stationary in order one $I(1)$ and hence we conclude that there is a long run integration process for inflation. Afterwards, we calculate long run mean value "theta" and speed of adjustment parameter "kappa" using Johansen Co-integration technique. We re-estimate kappa, sigma and drift parameter "mu" into SDEs. Our SDEs follows white noise and Weiner process (Brownian motion). We extend our Brownian motion process to Ito's process under Reiman integral equation in order to measure the validity of our hypothesis. We calculate SDEs with inflation and then integrate it with non-differentiable function. We use Ito's process; Ornstein-Uhlenbeck process; Heston Process, square root diffusion and Vasicek Model separately to examine the fluctuations for inflation based on caliberation of the model which is feasible and consistent. For the caliberation, we follow Heston process of SDEs. We then measure the transition densities to obtain the distribution of inflation particle under SDEs. In final, we follow Ornstein-Uhlenbeck process that describes the velocity of massive Brownian particle (Inflation). In fact we follow indirectly statistical properties of mathematical model in our equation that inflation follows Stationary, Gaussian and Markovian nontrivial process.

\section{Results and Discussion}

We employ inflation variable to calculate inflation volatility for Turkey. For this reason, we calculate ADF and KPSS in order to measure whether a variable contains a stationary process or not and we found that inflation is stationary in first difference. We extract the drift parameter from ADF test and put the value into SDEs. Under Autoregressive Conditional Heteroskedasticity model, we calculate the sigma (diffusion parameter $=0.33$ ). The stochastic differential equation for the inflation is as follow:

$$
\text { dinflation }_{t, i}=\mu_{i}\left(\operatorname{Inflation}(t)_{i}, t\right)+\sigma_{i}\left(\operatorname{Inflation}(t)_{i}, t\right) d W(t)_{i}
$$

$\mu_{i}$; explains a drift parameter; $\sigma_{i}$ shows the stochastic volatility and $W(t)_{i}$ is the Weiner process whose covariance matrix is stochastic volatility sigma. We calculate the ex-ante inflation by applying 7 period span and 100 time steps under 10 steps replications via simulation dynamics. In figure 1, our results are based on the SDEs theory that explain the crisis during 2008. The volatility in inflation was a bit higher during 2008-2011 as compared to 2012-2013. It seems that consumers, businesses and investors behaviour were more volatile during 2008-2011.

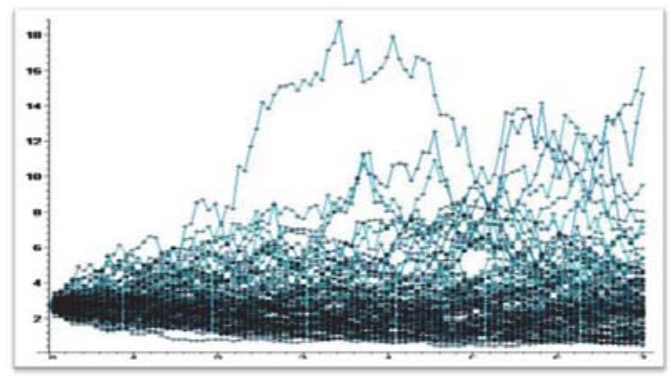

Figure 1. 
In our early discussion, we explained inflation is stationary at first difference which means that there is long run cointegration relationship. The short and long run volatility pattern of inflation can be seen through Heston process of SDEs, however, in the same manner, the short and long run parametric values can be extracted from ARDL or Johansen CoIntegration with vector error correction model that are econometric models. Heston process of SDEs in follows in equation 2.

$$
\begin{aligned}
& d S_{t}=\mu_{i}(S(t) d t)+\sqrt{V(t)} S(t) d W(t)_{i} \\
& d V(t)=\mathrm{K}(\theta-V(t)) d t+\sigma \sqrt{V(t)} d W(t)_{i}
\end{aligned}
$$

$\mu_{i}$ is the drift parameter of inflation; $\theta$ is the long run value of inflation; ${ }^{\mathrm{K}}$ shows the speed of mean reversion that is the same value of error correction value for the inflation and $\sigma$ is the stochastic volatility process. We calculate $\sigma$ value using (GARCH) process which is 0.33 and obtain $\mu_{i}$ that provides us 0.000662 ; volatility parameter value $\sigma$ contains $0.33 ; \theta$ value from the model provides 0.0597 value and ${ }^{\mathrm{K}}$ value have -0.0019 value in model. Diffusion equation is explained in equation 4 and 5.

Diffusion equation of Heston process follows the matrix form;

$$
\begin{aligned}
& \left(\begin{array}{cc}
\sqrt{\text { Inflation }(t)} \rho \text { Inflation }(t) & \sqrt{\text { Inflation }(t)} \text { Inflation }(t) \sqrt{-\rho^{2}+1} \\
\sqrt{\text { Inflation }(t)} \sigma & 0
\end{array}\right) \\
& \text { Inflation }=\left(\begin{array}{cc}
\beta e^{\alpha t+\beta W(t)} & 0 \\
\beta e^{\alpha t+\beta W(t)+\gamma W_{0}(t)} & \kappa e^{\alpha t+\beta W(t)+\gamma W_{0}(t)}
\end{array}\right)
\end{aligned}
$$

We run 700 simulation iterative schemes with Heston process for inflation. The sample paths of the state variables follow random pattern. Equation 4 shows that the source of randomness of inflation is correlated with $\rho$. We calculate the distributional mechanism in which the inflation follows Weiner process in a random manner. In equation 5 , we show lower triangular matrix to calculate inverse and Eigen values of matrices that span the rows and columns of matrix. The span and basis forms predict the exact distributional property with diffusion of inflation for certain periods. In order to calculate Heston process, reader should bear following points in mind. The first thing is to implement close form solutions for standard inflation volatility with jump diffusion. Jump diffusion basically tries to maximize the numeric for speed that we discuss in equation 6 using calibration. We verify the claim of closed form solution with a Monte Carlo Simulation (MC) and solve our model of transition densities with finite difference method (FDM). We finally calculate the sensitivity of inflation volatility with square root diffusion under Monte Carlo Simulation.

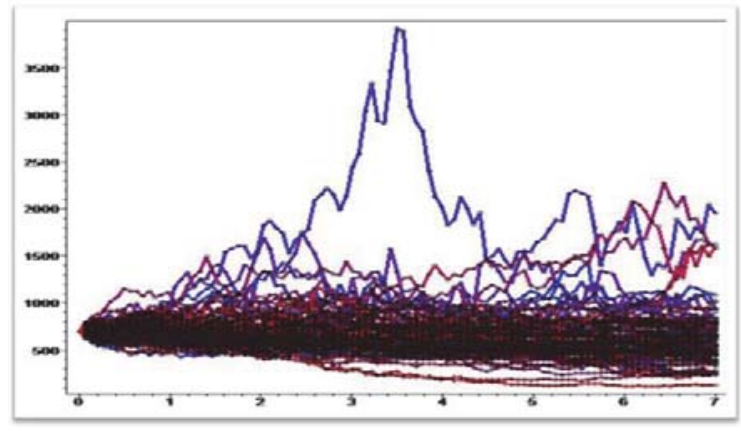

\section{Figure 2.}

After calculating local versus global optimization for inflation volatility with non-linear programming by using time dependent coefficients and piecewise constant parameter along with inflation volatility we obtain figure two that shows that Heston process follow a tendency of long run inflation value $\theta=0.0597$ towards mean reversion at the rate of $\left[-\frac{597 t}{10000}\right] \omega$ inflation volatility is ascending. The state variable follows the rising path of inflation as the transition happens during 2008 to 2011. The same pattern follows the inflation volatility from ex-ante period to afterwards ex-post period. We discuss expost process under Euler Discretization in our appendix. In figure 2 inflation follows non-deterministic process under 
Feller condition of stochastic volatility in inflationary dynamics. We assume the parameter of inflation is time dependent in order to have less rigidity in framework for inflation. We compare our results with Grzelak and Oosterlee (2011) and furinsh that under stochastic volatility of the Heston process, it resolved the problem in Black Scholes pricing formula and gives us a better explanation for the underlying measurement of inflation volatility. Hence, in our case the distribution under Heston process follow the stochastic behaviour during ex-ante process. We can also evaluate the past experience of Turkey monetary policy and inflation mechanism. Turkey destabilizes its currency as compare to dollar progressively because of inflation volatility. Turkish inflation grown up significantly in December 2014 and it is still rising.

Government intervened under Keynesian mechanism in order to chase the equilibrium for inflation. Policy makers focus to predict the inflation using DSGE, BVAR and other complicated model, however, they are unable to prognosticate the true picture of inflation and interest rate for Turkey. In our case, we declare that inflation is predictable under SDE's which is less complicated, reliable and efficient. Nevertheless, there are uncertain and fluctuations in interest rate and inflation Turkey from ex-ante period to ex-post period that used unsystematic behaviour. Turkish Investors, businesses, traders and consumers are rational and choose their savings and consumptions based on the announcement of monetary policy.

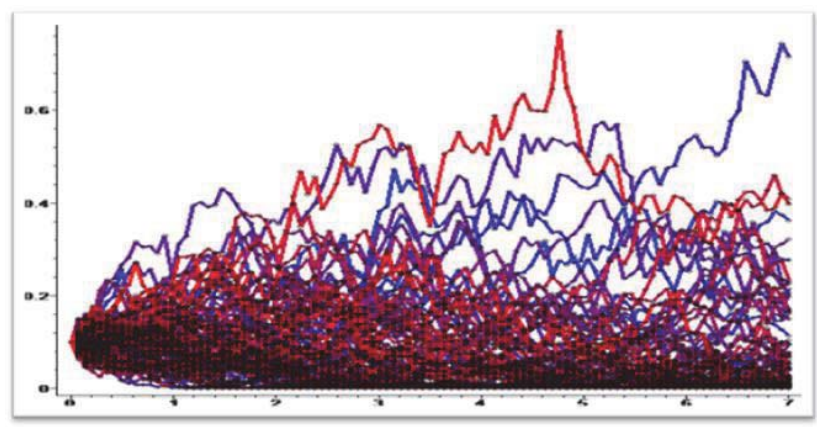

\section{Figure 3.}

Figure 3 calculate the transition densities for 7 period span of inflation. The importance of transition probability is based on Borel sigma algebra with Markov switching regime that explains the predictable pattern for economic variable inflation. We evaluate forward evolution of its transition density for inflation with "Kolmogorov forward equation (Known as FokkerPlank Equation) using fixing initial state Wiener steps. We then obtained the following result of general solution for inflation in equation 6.

$$
\text { Inflation }(\mathrm{t})=\frac{331}{500000}+\frac{24669}{500000} e^{-\left[\frac{597 t}{10000}\right]}
$$

By replicating theta, mu, sigma and tau we incorporate our values into Ornstein-Uhlenbeck process to validate the assumption that all parameters are unbiased and efficient. We received the positive intercept that follow initial value is normally distributed with time invariant measurement for inflation. The inflation particle of slope coefficients is negative exponential that claim the consistency of long run parameter with Euler Discretization; while intercept value is positive and rising. Positive intercept means that there was inflationary pressure during 1994, 2001 and 2008. Using expectation in general solution, transition densities show the sign of inflation is rising and in ex-post period and there is a likelihood of inflation volatility after 2013. We have seen using square root diffusion that there will be inflation volatility after ex-ante period and hence Investors, businessman and traders should aware of the uncertainty behavior.

$$
\tau=8.375 e^{[0.119 t]}-8.375
$$

Equation 7, we calculate tau for inflation volatility. Tau is the uncertainty parameter for inflation volatility in our Ornstein-Uhlenbeck process that explain the positive pattern. The standard pattern says that under CKLS (Chan Karolyi Longstaff Sanders) process can be solved under the closed form of tau from ${ }^{[0 \rightarrow 1]}$. Nevertheless, the unbiased estimate corresponds to negative intercept of tau via positive conventional form of exponent for volatility. We calculate GARCH term that follow negative parametric value with tau value for inflation from positive response of ex-post period. Our Ornstein-Uhlenbeck process tracks the equation;

$$
\text { Inflation }=t \rightarrow \mu_{0} e^{(-\theta t)}+\mu\left(1-\mu_{0} e^{(-\theta t)}\right)+\sigma e^{(-\theta t)} W(t)
$$


The expected value of inflation under Ornstein-Uhlenbeck process is 0.3121 and standard error for inflation is 0.0304. Based on the Ornstein-Uhlenbeck process we can certainly say that after 2014 and onward the inflation will be rising and volatile as it was in 2008-2011. The theta value "long run inflation" value is positive but with negative exponential form in equation 6 which implies the convergence and follows mean reversion process for inflation volatility, however, there is possibility that inflation would rise and unsystematic behaviour would slash the consumers and investors spending after ex-ante period 2014. Our results illustrate that Ornstein-Uhlenbeck process follow Brownian, Gaussian and Markovian process that follow mean reversion in the long run. In 2013 and onwards, the process follows unsystematic in continuous time or Weiner process. There might be tendency that inflation moves back to central location. We have surely observed that under Euler Discretization in ex-ante period, the long run inflation parametric value converges to its real value.

\section{Conclusion}

The parametric values for SDE's explain ex-ante and ex-poste inflation is foreseeable for Turkey. Previous studies uses complicated econometric models such as VAR and DSGE models that do not properly explain the true picture of forecasting and hence these modles are completely blemished. We predict the inflation using SDEs under Ito's process, Weiner process, Vasicek model and Ornstein-Uhlenbeck process which provide better forecasting. We can easily realize that mathematical techniques are robust and give enough clues for inflation uncertainty and inflation predictability. Under Euler Discretization and Unbiased Discretization process, the intensity of inflation volatility is converging towards long run parametric value of inflation. However, it took 4 to 5 years to achieve long run value for inflation. Investors, businessman and consumers are cognisant of the inflation volatility. The research work for inflation can be enhanced by incorporating more economic variables in study such as to demonstrate trade ${ }^{-}$off Phillips curve, liquidity preference and money market, yield to maturity ratio and terms structure for bonds market. Moreover, time span for inflation can be calculated by forecasting channel on the assumption of random generation process through Euler Discretization in future.

\section{References}

Apergis, N. (1997). Inflation Uncertainty, Money Demand, and Monetary Deregulation: Evidence From a Univariate ARCH Model and Cointegration Tests. Journal of Policy Modeling , 19 (3), 279-293.

Arize, A. C., Malindretos, J., and Grivoyannis, E. C. (2005). Inflation-Rate Volatility and Money Demand: Evidence from Less Developed Countries. International Review Of Economics and Finance , 14, 57-80.

Bal, T. i. (2000). U.S. Money Demand and the Welfare Cost of Inflation in a Currency-Deposit Model. Journal of Economics and Business, 52, 233-258.

Berganza, J. C., \& Broto, C. (2012). Flexible inflation targets, forex interventions and exchange rate volatility in emerging countries. Journal of International Money and Finance , 31 (2), 428-444.

Berument, M. H., \& Sahin, A. (2010). Seasonality in inflation volatility: Evidence from Turkey. Journal of Applied Economics, 13 (1), $39-$ 65.

Budina, N., Maliszewski, W., Menil, G. d., and Turlea, G. (2006). Money, Inflation and Output In Romania, 1992-2000. Journal of International Money And Finance, 25, 330-347.

Basco, E., D'Amato, L., and Garegnani, L. (2009). Understanding The Money-Prices Relationship Under Low and High Inflation Regimes: Argentina 1977-2006. Journal of International Money and Finance , 28, 1182-1203.

Castelnuovo, E. (2010). Trend inflation and macroeconomic volatilities in the post-WWII U.S. economy. The North American Journal of Economics and Finance , 21 (1), 19-33.

Castillo, C. (2014). Inflation targeting and exchange rate volatility smoothing: A two-target, two-instrument approach. Economic Modelling , 43, 330-345.

Clark, T. E., \& Davig, T. (2011). Decomposing the declining volatility of long-term inflation expectations. Journal of Economic Dynamics and Control , 35 (7), 981-999.

Dreger, C., and Wolters, J. (2014). Money Demand and The Role of Monetary Indicators in Forecasting Euro Area Inflation. International Journal of Forecasting , 30, 303-312.

El-Shagi, M., and Giesen, S. (2013). Money and inflation: Consequences of The Recent Monetary Policy. Journal of Policy Modeling , $35,520-537$.

De Santis, R. A., Favero, C. A., and Roffia, B. (2013). Euro Area Money Demand and International Portfolio Allocation: A Contribution to Assessing Risks to Price Stability. Journal of International Money and Finance , 32, 377-404.

EDGE, R. M., \& GÜRKAYNAK, R. S. (2010). How Useful Are Estimated DSGE ModelForecasts for Central Bankers? Brookings Papers on Economic Activity , 209-259.

Ginindza, M., \& Maasoumi, E. (2013). Evaluating inflation targeting based on the distribution of inflation and inflation volatility. The North American Journal of Economics and Finance , 26, 497-518. 
Hossain, A. A. (2010). Monetary Targeting for Price Stability in Bangladesh: How Stable is its Money Demand Function and The Linkage Between Money Supply Growth and Inflation? Journal of Asian Economics , 21, 564-578.

Jawadi, F., and Sousa, R. M. (2013). Money Demand in The Euro Area, The US and The UK: Assessing The Role Of Nonlinearity. Economic Modelling , 32, 507-515.

Kim, S. (2004). Inflation volatility, government debts, and the fiscal theory of the price level. Economics Letters, 85 (1), $117-121$.

Oomes, N., and Ohnsorge, F. (2005). Money Demand and Inflation in Dollarized Economies: The Case of Russia. Journal of Comparative Economics, 33, 462-483.

Pricea, S., and Nasim, A. (1999). Modelling Inflation and The Demand for Money in Pakistan; Cointegration and The Causal Structure. Economic Modelling , 16, 87-103.

Reynard, S. (2007). Maintaining Low Inflation: Money, Interest Rates, and Policy Stance. Journal of Monetary Economics , 54, 14411471.

Singor, S. N., Grzelak, L. A., van Bragt, D. D., \& Oosterlee, C. W. (2013). Pricing inflation products with stochastic volatility and stochastic interest rates. Insurance: Mathematics and Economics , 52 (2), 286-299.

Appendix: Local Volatility for Inflation

$$
\begin{aligned}
C:= & 38.94003916+38.94003916 \operatorname{erf}\left(3.030303029 \ln \left(\frac{100 .}{K}\right)-0.6741363635\right)- \\
& 0.9996900480 K \\
& \left(0.5000000000+0.5000000000 \operatorname{erf}\left(3.030303029 \ln \left(\frac{100 .}{K}\right)-0.8391363635\right)\right)
\end{aligned}
$$

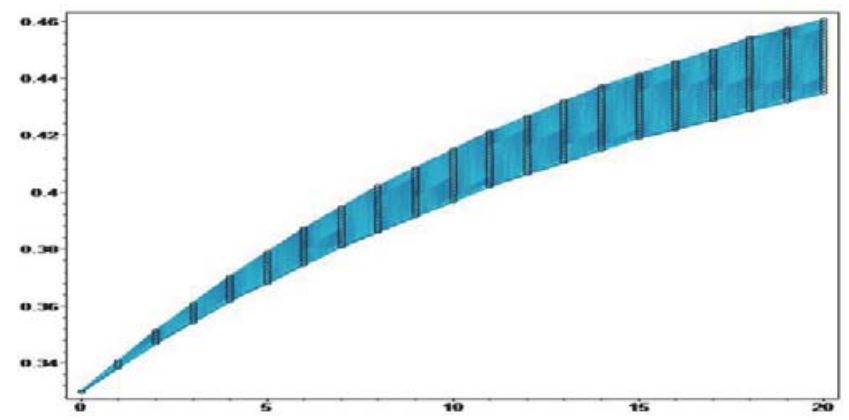

Figure 4: Inflation Deviation under Vasicek Model [Time Steps 10, 20 Replications]

$$
q:=t \rightarrow r 0 \mathrm{e}^{(-\theta t)}+\mu\left(1-\mathrm{e}^{(-\theta t)}\right)+\sigma \mathrm{e}^{(-\theta t)} \mathrm{W}(t)
$$

Figure 5: [9 Periods, 50 Time Steps with 20 Replications] Square Root Diffusion Volatility for Inflation]

Square root diffusion can be solved under a condition that SDEs with Ito's process which fulfils linearity and additively property under isometric plane. Our square root follows one dimension Brownian motion for short run volatility of inflation. We then simulate our square root diffusion with Euler Discretization and unbiased Discretization for inflation.

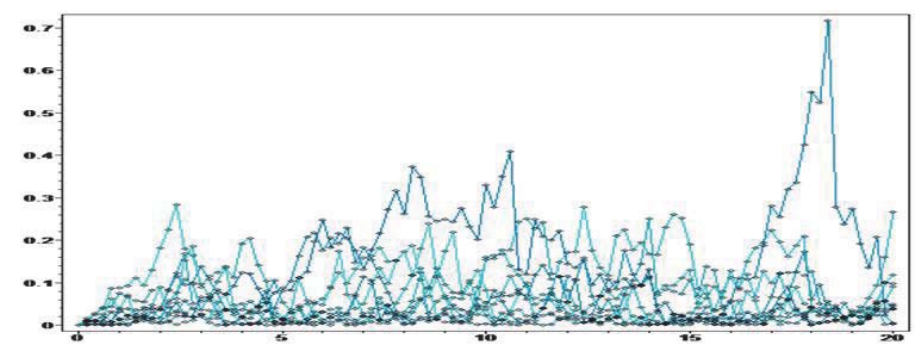

Figure 6: Comparison with Euler Discretization and Unbiased Discretization for Inflation [Volatility Parameter (0.33) Under GARCH Process] 
Inflation $:=\mathrm{x}(t)=\frac{593}{10000}-\frac{58677}{1000000} \mathrm{e}^{\left(-\frac{t}{2}\right)}$

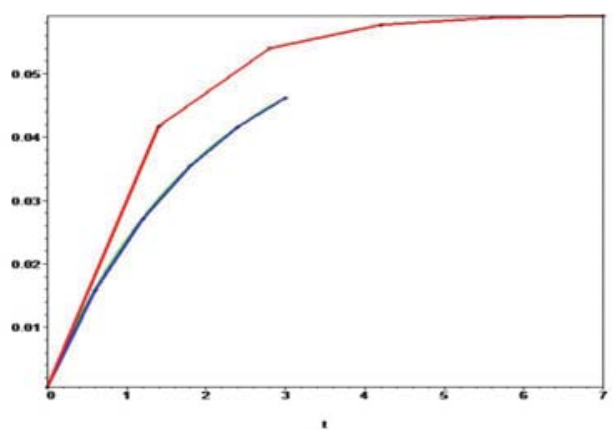

By setting sigma, theta, mu and tau values into square root diffusion equation, we obtain equation 10. Equation 10 proves that inflation volatility is growing subsequent to 2014 year; whilst this inclination is falling and converging towards its long run mean value of inflation. In figure 6 , we choose three scenarios to compare with square root diffusion volatility parameter "0.33" with initial guess (0.3) in volatility to calculate unbiased Discretization. Under "Heston model" of stochastic volatility and vector of SDEs with diffusion parameter explain that "inflation with exact method and biased method are covered. We can comprehend from figure 6 that graphic performance explains sigmoid process for inflation convergence in the long run. The most interesting result in this graph is; that our long run calculated inflation from econometric model is approximately converging to SDE's Euler Discretization process. However, we didn't calculate the exact time span for convergence after volatility. The calculation of time for this volatility will be another interesting research topic for this study. 